\title{
Potential inpatient hospital care accessibility scores: association with healthcare utilization and non-hospital care service accessibility
}

Fei GAO ( $\sim$ fei.gao@ehesp.fr )

Ecole des Hautes Etudes en Sante Publique

Matthieu Jaffrelot

ENSAI

Séverine Deguen

Ecole des Hautes Etudes en Sante Publique

Research article

Keywords: Potential accessibility, hospital care, non-hospital care, length of stay, E2SFCA, administrative data uses

Posted Date: December 21st, 2020

DOI: https://doi.org/10.21203/rs.3.rs-42105/v2

License: (c) (i) This work is licensed under a Creative Commons Attribution 4.0 International License. Read Full License 


\section{Potential inpatient hospital care accessibility scores: association with healthcare utilization and non-hospital care service accessibility}

Fei Gao ${ }^{1,2}$, Matthieu Jaffrelot ${ }^{1,4}$, Séverine Deguen ${ }^{1,3}$

\section{Author Affiliation}

${ }^{1}$ EHESP, F35000 Rennes, France

${ }^{2}$ L'équipe REPERES, Recherche en Pharmaco-épidémiologie et recours aux soins, UPRES EA7449, Rennes, France.

${ }^{3}$ INSERM, Sorbonne Université, Institut Pierre Louis d’Épidémiologie et de Santé Publique, IPLESP, Department of social epidemiology, F75012 Paris, France ;

${ }^{4}$ Univ Rennes, Ensai, F-35000 Rennes, France

\section{Address for correspondence}

Fei GAO

EHESP School of Public Health, Department of Quantitative Methods for Public Health, Rennes, France

Avenue du Professeur Léon Bernard - 35043 Rennes - France

Tel: + 33299022535

Fax: + 33299022676

Email: fei.gao@ehesp.fr 


\section{Abstract}

Background: Optimal healthcare access improves people's health status and decreases health inequalities. Many studies demonstrated spatial access importance in health outcomes. Recent studies assessed spatial healthcare access using the enhanced two-step floating catchment area (E2SFCA) method. The study aim was to build a hospital facility access indicator at a fine geographic scale and to assess the impact of spatial accessibility to inpatient hospital care and non-hospital care services on the length of hospital stay (LOS).

Methods: This study focused on the $\geq 75$-year-old population of the Nord administrative region of France. Hospital spatial accessibility was computed with the E2SFCA method, and then the LOS score was calculated from the French national hospital activity and patient discharge database. Linear regression models were used to analyze the relationship between LOS and spatial accessibility to inpatient hospital care and to three types of nonhospital care services (general practitioners, physiotherapists, and home-visiting nurses).

Results: Overall, there were 19.0 beds in Medical, Surgical and Obstetrics (MCO) facilities and 5.58 beds in Postoperative and Rehabilitation Care facilities (SSR) per 10,000 inhabitants, but with important geographic variations. Accessibility to hospital services was higher for people in large urban areas, despite the dense population and the higher demand. In 2014, the mean LOS scores were 0.26 for MCO and 0.85 for SSR, with a non-homogeneous geographical repartition. The linear regression analysis revealed a strong negative and significant association between LOS and non-hospital care accessibility. 
Conclusions: This is the first study to measure spatial accessibility to inpatient hospital care in France using the E2SFCA method, and the first to investigate the relationship between healthcare utilization (LOS) and spatial accessibility to inpatient hospital care facilities and three types of non-hospital care services. Our findings should help to take decisions about deploying additional beds and to identify the best locations for non-hospital care services. Moreover, they should also help to improve access, and to ensure the best coordination and sustainability of inpatient and outpatient services, in order to better cover the population's healthcare needs. Other international studies using multiple consensual indicators of healthcare outcomes and accessibility and sophisticated modeling methods should be developed.

Keywords: Potential accessibility, hospital care, non-hospital care, length of stay, E2SFCA, administrative data uses 


\section{BACKGROUND}

Access to healthcare is widely recognized as the foundation of any high-performing healthcare system. Ensuring a high degree of healthcare access improves people's health status and decreases health inequalities. Guaranteeing equal accessibility to healthcare facilities for everyone is an essential goal for international political organizations and national governments [1-5].

Access to healthcare can be determined by two complementary dimensions: spatial and non-spatial dimensions [6]. Spatial access, also known as potential access, refers to the spatial distribution of healthcare facilities, and the possibility to reach healthcare activity locations or services from a given position or by an individual [7-11]. Spatial access varies across space and time, and consequently it is affected by location relationships and travel impedance. On the other hand, non-spatial access mainly focuses on socioeconomic conditions and cultural background, such as ethnicity, income, social class, education, and language ability [12]. Spatial access is recognized as an important component in the evaluation of the overall access to healthcare [13] and plays an important role in health outcomes [14-19].

The assessment of spatial access to healthcare services should take into account the care provided by various facility types. Indeed, in many countries, the healthcare system is based on a combined architecture: non-hospital care based on general practitioners who can address patients to other healthcare professionals (e.g. nurses, physiotherapists, specialists doctors) $[20,21]$. Non-hospital care represents the most significant primary care contributor 
in many countries, including developing countries $[22,23]$, because it ensures an effective and generally faster service that covers the large majority of personal healthcare needs [24], and acts as the principal point of continuing care for patients [25]. Nevertheless, hospitals remain one of the key healthcare actors. Inpatient care provided by hospitals represents a major part of people's consumption of healthcare and medical goods, especially in Europe. In 2017, nine of the ten countries with the highest hospital discharge rates worldwide were European Union member states [26]. Coordination and organization between inpatient hospital care and primary care are critical for a successful healthcare system. This is particularly true during pandemic situations when hospitals may reach a point of "complete saturation" due to increased patients' influx. In these situations, non-hospital resources, as the most significant primary care contributor, might anticipate and limit the number of hospitalizations and the consumption of hospital-linked resources [27, 28]. A consolidated spatial organization of non-hospital medical services in the territory can complement hospital services and increase healthcare efficiency [29].

Therefore, it is essential to assess accessibility to non-hospital care and inpatient hospital care, and also to examine whether there is interactions between them [30]. However, much of the recent research on geographic healthcare access has focused on assessing the potential access to healthcare services, rather than on their utilization [31, 32]. However, to address the variety of demands by patients, providers and policy makers, it is necessary to measure the potential access to and also the utilization of health services. Furthermore, healthcare utilization is linked to interactions between accessibility to non-hospital and inpatient hospital care. For instance, the length of hospital stay, one of the classical indicators of healthcare utilization, is associated with primary care supply. Kjekshus et al, 
found that the ability of primary healthcare services to take care of discharged patients has a significant impact on the hospitalization length, particularly for elderly people [33].

In this context, the aim of this study was to analyze the relationship of healthcare spatial accessibility and health service utilization following three main complementary steps: 1) to build an inpatient hospital care access indicator at a fine geographic scale; 2 ) to measure health service utilization using the length of hospital stay; and 3) to investigate the impact of spatial accessibility to inpatient hospital care and non-hospital healthcare services on the length of hospital stay. This analysis focused on the $\geq 75$-year age group of the total population of the Nord administrative region of France. Indeed, older adults represent a growing proportion of the total population and is expected to double by 2050 [34]. In France, the percentage of populations aged 75 years or more was of $9.7 \%$ in 2020 and is expected to rise to $16 \%$ by 2050 [35], with an increasing number of age-related diseases such as chronic diseases. Different healthcare resources are involved in their management: hospital facilities and primary care professionals (e.g. general practitioners, physiotherapists, and home-visiting nurses). Additionally, as their recovery period after a hospital stay is often longer, their length of stay could be more influenced by the ability of the primary healthcare services to follow them. 


\section{METHODS}

2.1. Study setting and population

This study was carried out in the Nord administrative region that is located in the north of France, with a surface area of $5743 \mathrm{~km}^{2}$ and a population density of 456 inhabitants per $\mathrm{km}^{2}$. Multiple non-hospital care accessibility indicators are available for this department [36-38]. Moreover, it has been shown that edge effects lead to minor accessibility variations in this area [39]. The study focused on the $\geq 75$-year-old population of this area.

\subsection{Data sources and statistical unit}

Multiple data sources were combined for the present study:

(1) The accessibility to non-hospital care was described using the Localized Potential Accessibility (Accessibilité potentielle localisée: APL) database [40]; Based on the E2SFCA method, APL indices are available at national level but only for eight types of self-employed practitioners: general practitioners, physiotherapists, homevisiting nurses, gynecologists, dental surgeons, midwives, pediatricians, and ophthalmologists. For this study, the APL indices for general practitioners, physiotherapists, and home-visiting nurses were used because these three types of health professionals could contribute substantially to the primary care services to older adults. Furthermore, the healthcare provided by them might interact with inpatient hospital care.

(2) The number of available beds in each hospital was extracted from the Annual Statistical Survey of Healthcare Facilities 2014 database (Statistique Annuelle des Établissements: SAE) [41]. Facilities were classified in two categories: Medical, 
Surgical and Obstetrics facilities (Médecine, Chirurgie, Obstétrique: MCO) and Postoperative and Rehabilitation Care facilities (Soins de Suite et de Réadaptation: SSR);

(3) The postal address of each hospital was obtained from the National File on Health and Social Institutions (Fichier national des établissements sanitaires et sociaux: FINESS) [42], and then converted into latitude and longitude using the French National Address Database [43];

(4) The Length Of Stay (LOS) was calculated from the French national discharge database that collects hospital activity and patient discharge data [44-47]. We used MCO and SSR inpatient care data for the year 2014;

(5) The number of $\geq 75$-year-old people in the Nord administrative region was obtained from the 2016 French national Census [48].

The statistical unit was the French Geographic Code unit (FGC), defined by the French national discharge database. The FGC is approximately equivalent to the municipality postal code. The Nord department is divided into 240 FGCs with a population ranging from 1000 to 227000 residents per FGC.

\subsection{Methodology}

First, the E2SFCA method was implemented to compute the hospital spatial accessibility by combining geographical, supply, and demand factors. Second, the LOS indicator was estimated for each FGC unit. Third, linear regression models were used to analyze the 
relationship between LOS and spatial accessibility to inpatient hospital care and also to the three types of non-hospital care services (general practitioners, physiotherapists, and homevisiting nurses). The final variables included in the model for further analysis and the categories of facilities for which they are available are shown in Table 1.

2.3.1. Assessing hospital care spatial accessibility using the E2SFCA method

The hospital facility access indicator was built using the enhanced two-step floating catchment area (E2SFCA) method, one of the most widely used gravity-based approaches. Based on this method, two different spatial indicators were constructed in France: the localized potential accessibility score developed by the French Research Institute in Health Economic institute (IRDES) at the municipality level in 2011 [36], and at the census block level for the Greater Paris area in 2019 [37]. In 2016, the index of spatial accessibility (ISA) at the census block level was implemented by Gao and al. [38]. However, one common limitation of these studies was the focus on non-hospital care services only. So far, no French indicator based on the E2SFCA method has measured the access to hospital care at a very fine geographic scale.

The E2SFCA method [49] was implemented in two steps, as follows:

Step1: For each hospital center $j$ with a MCO or SSR facility, the number of beds in the MCO or SSR facility $S_{j}$ was counted and the population living in the FGC area $k$ and located within a threshold drive time $d_{\max }$ from the hospital center $j$ (i.e. catchment area $j$ ) was estimated. 
Then, the bed-to-population ratio $R_{j}$ within the catchment area $j$ was determined with Equation 1:

$$
R_{j}=\frac{S_{j}}{\sum_{k \in\left\{d_{k j} \leq d_{\max }\right\}} P_{k} * w\left(d_{k j}\right)}
$$

where $P_{k}$ is the patient population in the FGC area $k$ the centroid of which falls within the catchment area $j$ (i.e. $d_{k j}<d_{\max }$ ), $S_{j}$ is the number of beds available in the hospital center $j$, and $d_{k j}$ is the driving time between the FGC area $k$ and the hospital center $j$, and $w()$ is a weighted decay function that depends on the driving time $d_{k j}$.

Step 2: For each population location $i$, all MCO or SSR facility locations $j$ that were within the threshold driving time $d_{\max }$ from location $i$ (i.e. catchment area $l$ ) were estimated, and all $R_{k}$ for the catchment area were summed to calculate the Index of Spatial Accessibility (A $I$ ) at location $i$ (Equation 2):

$$
A_{i}=\sum_{j \in\left\{d_{i j} \leq d_{\max }\right\}} w\left(d_{i j}\right) R_{j}
$$

where $R_{j}$ is the bed-to-population ratio of the hospital center $j$, and $d_{i j}$ is the driving time between the FGC area $i$ and the hospital center $j$.

All driving times from $i$ to $j$ were obtained using Google Maps and then computed by SAS version 9.3 [50]. The E2SFCA accessibility score was calculated with the MYSQL program. The definition of the decay function $w()$ and time thresholds were previously explained [38]. Briefly, when the travel time to a MCO and to a SSR facility was longer than 41 and 69 minutes, respectively, that hospital was considered too distant to be accessible. These distance decay parameters were used as cut-off distances to define the catchment areas. 
The spatial accessibility index $A_{i}$ obtained with the E2SFCA method is a special form of physician-to-population ratio, expressed as the number $(N)$ of beds per 10,000 inhabitants. Higher scores indicate higher accessibility.

$$
\operatorname{LOS}_{i}=\sum_{g>75} \frac{d m s_{g}}{P_{g}}
$$

Equation (3)

\subsubsection{Measuring health service utilization using the LOS indicator}

The LOS was defined as the mean hospital stay length of elderly people ( $\geq 75$ years of age) relative to the total $\geq 75$-year-old population in a given FCG (Equation 3 ). In this equation, $g$ represents the three groups of $\geq 75$-year-old people (75-84, $85-94$ and $>95$ years), and $P g$ the corresponding total population for that age group. The numerator represents the average length of stay of each age group, standardized to the total population for that age group (inpatients or not) in the denominator.

2.3.3. Linear Regression Model and composite accessibility indicator by principal component analysis

A multiple ordinary least squares regression model was applied to investigate the relationship between Length Of hospital Stay ([LOS_MCO]_hospital and [LOS_SSR]_hospital as the dependent variable), the hospital accessibility indicators ([ISA_MCO]_hospital and [ISA_SSR]_hospital), and the accessibility to the three non-hospital practitioners: general practitioners, physiotherapists, and home-visiting nurses ([APL]_non-hospital) (Equation 4). 
As our variables were log-normally distributed, they were normalized using the logarithmic Napierian function.

$$
\ln \left(L O S^{*}\right)=\beta_{0}+\beta_{1} \cdot \ln \left(I S A^{*}\right)+\sum \beta_{n} \cdot \ln \left(A P L_{n}\right)+\varepsilon ; \text { with } \varepsilon \approx i i d\left(0 ; \sigma^{2}\right)
$$

where * indicates the [LOS_MCO]_hospital (with the corresponding [ISA_MCO]_hospital as independent variable) and [LOS_SSR]_hospital (with the corresponding [ISA_SSR]_hospital as independent variable), and $n$ defines the number of different types of non-hospital healthcare professionals considered in the analysis $(n=3$ : general practitioners, physiotherapists, and home-visiting nurses).

To describe the global accessibility to the three non-hospital services, a composite APL indice was built using principal component analysis. In Equation (5), the three [APL]_non-hospital types are replaced by the [Composite_APL]_non-hospital. This approach offers the advantage of taking into account the correlation between each [APL]_non-hospital value to assess the accessibility to non-hospital services.

$$
\ln \left(\text { LOS }^{*}\right)=\beta_{0}+\beta_{1} \cdot \ln \left(I S A^{*}\right)+\beta_{2} \cdot \ln (\text { Composite APL })+\varepsilon ; \text { with } \varepsilon \approx \text { iid }\left(0 ; \sigma^{2}\right) \quad \text { Equation (5) }
$$

In summary, equations (1) and (2) were used to etimate the [ISA_MCO]_hospital and [ISA_SSR]_hospital variables. Equation (3) helped to etimate the [LOS_MCO]_hospital and [LOS_SSR]_hospital variables that are $Y$ variables in the regression model. Equation (4) is the OLS regression model to investigate the relationship between LOS, inpatient hospital care accessibility and accessibility to the three non-hospital services. Equation (5) is a variation of 
equation (4) in which the three [APL]_non-hospital types were replaced by the [Composite_APL]_non-hospital variable to take into account their correlation.

\section{3. $\underline{\text { RESULTS }}$}

3.1 Descriptive analysis and spatial distribution of the [ISA_MCO]_hospital and [ISA_SSR]_hospital values

In total, there were 240 FGC units in the Nord administrative region. Table 2 summarizes the [ISA_MCO]_hospital and [ISA_SSR]_hospital values. On average, there were 19.0 beds in MCO and 5.58 beds in SSR for 10000 inhabitants. The values revealed important variations among FGCs with a standard deviation of 10.6 and 2.23 beds per 10000 inhabitants in MCO and SSR, respectively. Almost $25 \%$ of the population had access to fewer than 10 beds in MCO and 4 beds in SSR.

To compare the spatial distribution of the [ISA_MCO]_hospital (a) and [ISA_SSR]_hospital (b) values per 10000 inhabitants (Figure 1) within the Nord administrative region, scores were categorized in five classes using the Jenks Natural Breaks algorithm [51], from low to high accessibility. The Jenks Natural Breaks algorithm assigns values to a given number of classes with the objective of minimizing the variance within classes, while maximizing the betweenclass mean values. The highest [ISA_MCO]_hospital values ([24.04; 32.71] and [32.72; 39.28]) were observed in urban areas located in the northern part of the studied territory, close to Dunkerque, and also in the center, around Lille, Roubaix and Tourcoing. Conversely, the lowest values were observed mostly in the southern part and around Hazebrouck. The highest [ISA_SSR]_hospital values $([6.05 ; 7.14]$ and $[7.14 ; 9])$ were concentrated in the middle part of the region, whereas access was lower in the north and south. These findings showed that 
accessibility to hospital services is higher for people in large urban areas, despite the dense population and consequently the higher demand.

3.2 Elderly population and [LOS]_non-hospital spatial distribution

The elderly population was not homogeneously distributed over the studied territory. The percentage of $\geq 75$-year-old inhabitants varied from $3.79 \%$ (in the north-west area around Dunkerque, and in the center, particularly the cities of Roubaix, Lille and Villeneuve d'Ascq) to 11.91\% (around Bailleul and Hazebrouck and below the Valenciennes-Cambrai line) (Figure 2).

Analysis of the [LOS_MCO]_hospital and [LOS_SSR]_hospital values for the $\geq 75$-year-old population in the Nord administrative region (Table 3) showed that in 2014, the mean [LOS _MCO]_hospital and [LOS_MCO]_hospital values were 0.26 and 0.85 , respectively. The spatial variation was significant, with standard deviations of 0.20 and 0.92 for MCO and SSR, respectively.

Analysis of the [LOS_MCO]_hospital and [LOS_SSR]_hospital score distribution in the studied region highlighted a non-homogeneous repartition with higher values close to the border with other French regions, especially in the southern part (Figure 3 and Figure 4). From Dunkerque to Bailleul and also around Tourcoing, Roubaix, Lille and Orchies, LOS scores were lower. This suggests the existence of spatial dependencies in LOS distribution within the studied territory. This hypothesis was confirmed with the Moran test $(p$-value $=0.000$ for both [LOS_MCO]_hospital and [LOS_SSR]_hospital scores). 
3.3 Determinants of the [LOS_MCO]_hospital and [LOS_SSR]_hospital values The OLS regression analysis was used to investigate the determinants of the [LOS_MCO]_hospital and [LOS_SSR]_hospital scores separately at the FGC scale. This analysis (regression coefficient estimates and the corresponding $p$-values are in Table 4) showed that for the [LOS_MCO]_hospital score, two variables were significant ( $p$-value $<0.01$ ): global spatial accessibility to the three types of non-hospital care services ([Composite_APL]_nonhospital) and spatial accessibility to MCO facilities ([ISA_MCO]_hospital). Both variables revealed a strong negative association, suggesting that LOS were shorter for patients living in areas with easier access to non-hospital care services and MCO facilities. The SSR analysis also suggested that better accessibility to non-hospital care services might decrease LOS. However, the spatial accessibility to SSR facilities became non-significant.

\section{DISCUSSION}

\subsection{Summary of the results}

To our knowledge, the present study is the first to investigate the relationship between healthcare utilization (LOS) and spatial accessibility to inpatient hospital care facilities ([ISA]_hospital) and three types of non-hospital care services ([APL]_non-hospital, for general practitioners, physiotherapists, and home-visiting nurses). One of its main strengths is the cross-referencing of different data sources that allowed us to address several major public health issues.

First, following a previously developed methodology [38, 49], we estimated a measure of spatial accessibility to hospital care, for MCO and SSR facilities separately, at the French 
Geographic Code scale (FGC, approximately equivalent to the municipality scale). However, all previous French studies that used a similar methodology limited their accessibility measure to non-hospital care services [36-38]. The present study originality lies in extending the measure to hospital spatial accessibility, by taking into account the number of beds in MCO and SSR facilities, the car travel time, and the population distribution. The [ISA_MCO]_hospital and [ISA_SSR]_hospital variables were initially developed at the census block scale, then summarized to the FGC scale to investigate the association with the [LOS]_hospital indicator, because FGC is the smallest spatial level for which hospital data are available. Even at this spatial scale, [ISA]_hospital score distribution highlighted the unequal accessibility to MCO and SSR facilities within the study area. Analysis of the [ISA]_hospital score spatial distribution revealed that high-accessibility areas were mainly concentrated in the center of the investigated area. This can be partially explained by the large number of MCO and SSR facilities ( 25 of the 44 MCO and 24 of 30 the SSR centers) in these areas. However, we observed exceptions. Around Valenciennes, where there are three MCO hospitals with more than 400 beds in total, the [ISA]_hospital values were in the lower class. Conversely, although no MCO facility was located in or close to Bailleul, the [ISA]_hospital value for this area was quite high. This finding is coherent with the fact that the [ISA]_hospital variable provides a summary measure of two important and related components of accessibility: the volume of services available relative to the population size, and the proximity of services available relative to the population location. Therefore, although 400 MCO beds were located close to Valenciennes, the population's size was too important to obtain a high accessibility score. 
Then, we examined the association between the healthcare utilization indicator ([LOS]_hospital) and two accessibility scores ([ISA]_hospital and [APL]_non-hospital). Our analysis revealed a significant and negative association between the [LOS]_hospital and [Composite_APL]_non-hospital scores. In other words, a better accessibility to these nonhospital services corresponded to shorter hospital stays. One hypothesis is that in areas with better accessibility to the three non-hospital care services, hospitalizations are shorter because of the presence of effective outpatient care: ambulatory care and neighborhood healthcare services. For instance, home-visiting nurses and physiotherapists could be an alternative solution to SSR inpatient care. These results further support the hypothesis of complementary interactions between non-hospital and hospital services. These first findings should be complemented by research to determine the impact of primary care accessibility on length of stay.

\subsection{Comparison with the international literature}

Previous studies have paid attention to healthcare spatial accessibility and the question of whether healthcare activity could be rebalanced by expanding/strengthening the role of primary care relative to the more costly hospital (secondary) care. Most studies that focused on the use of primary care to reduce specialty/inpatient care were observational studies in which the rates of preventable hospitalizations were correlated with the self-rated access level [52] or distance $[53,54]$ to primary care services [55]. Few studies quantified both hospital and non-hospital care spatial accessibility with the E2SFCA method, and investigated their association with the length of hospital stay. The present study fills this gap by integrating three factors: spatial accessibility (1) to inpatient hospital care facilities and (2) to three types of non-hospital care (general practitioners, physiotherapists, and home-visiting 
nurses), and (3) length of hospital stays. As few studies have considered all three with a similar study design, comparison with the international literature was difficult. However, we could find few studies that investigated one or two of these aspects. First, although this is the first French study measuring hospital spatial accessibility using the E2SFCA method, other countries, for instance China [56] and Japan [57], already developed hospital accessibility scores following a similar approach. Second, other studies estimated the LOS to assess how primary care could contribute to reduce the demand of secondary care. In France, a study used the LOS for public-sector psychiatric facilities to investigate whether the development of alternatives to full-time hospitalization (such as ambulatory care, part-time hospitalization, and full-time outpatient care) may reduce the LOS [21]. They found a significant negative association and concluded that their study was the first to provide nation-wide evidence of the benefits of alternatives to full-time hospitalization in psychiatry. Similarly, our study is the first to show that non-hospital care services may reduce the length of stay in MCO and SSR facilities. Our findings and those of this study in psychiatry suggest that in some cases, non-hospital care services may constitute an alternative to hospitalization. Our results were obtained by modeling the association between healthcare utilization and accessibility to two types of healthcare services. These preliminary quantitative results should be supplemented by data on other healthcare outcomes frequently associated with the quality of care, such as unplanned readmission or mortality, as well as other aspects of accessibility (e.g. multiple consensual indicators of spatial/nonspatial healthcare access). Additional studies using sophisticated modeling methods should also be developed. The goal is to develop a consolidated approach to facilitate the spatial organization of non-hospital medical services in the territory with the aim of complementing hospital services and increasing healthcare efficiency. 


\subsection{Limitations}

As we used aggregated data at the FGC scale to assess associations between spatial accessibility to hospital and to three types of non-hospital care services and healthcare utilization, our findings may be subject to an ecological bias [38]. In addition, as previously explained, while the [ISA]_hospital index was estimated at the census block scale, the two other indicators ([LOS]_hospital and [APL]_non-hospital) were only available at the FGC scale, a cruder spatial scale. Thus, we could not take into account the spatial accessibility heterogeneity at the census block scale. For future research, we want to construct a LOS indicator at a finer scale using disaggregation techniques that take into account the population density.

In our analysis, we did not use statistical techniques that consider spatial autocorrelation. However, at the FGC scale, the Moran's indicator revealed the presence of spatial autocorrelation for both MCO and SSR LOS. To investigate more precisely the association of healthcare accessibility and utilization, the next step could be to consider the specificity of the study area by including its topological, geometric and geographic properties using spatial statistical models, such as the simultaneous autoregressive model, geographically weighted regression and Bayesian hierarchical model. Previous studies [58-62] demonstrated the robust properties of these models that can improve the methodology used to assess associations between healthcare spatial accessibility and utilization. For instance, Nicholas et al used Bayesian spatial models and location analysis methods to evaluate healthcare facility access [63]. 


\section{CONCLUSION}

This is the first study to measure spatial accessibility to MCO and SSR facilities in France using the E2SFCA method and to investigate the relationship between spatial accessibility to inpatient hospital care facilities and to non-hospital care services. It provides a basic understanding of the status of inpatient care within the studied area by showing the accessibility score variation across the territory and highlighting some areas with poor accessibility. This type of information is important to guide policy makers and local managers. Moreover, our findings support the hypothesis of complementary interactions between non-hospital and hospital services. Based on this research, policy makers and local managers could identify areas where additional beds or healthcare professionals should be allocated in priority.

Additional studies in other areas characterized by their own specificity have to be developed in order to confirm our results. It is also crucial to design new research approaches to understand the underlying mechanisms and processes that explain the interaction between inpatient hospital and non-hospital care services with the ultimate objective of better organizing and allocating medical resources. This research should help to take decisions about deploying additional beds and identifying the best locations for non-hospital care services, and also to improve access, to ensure the best coordination and to contribute to the sustainability of inpatient care and outpatient services, in order to better cover the health needs of the population. 


\section{ABBREVIATIONS}

APL: Localized Potential Accessibility

E2SFCA: Enhanced two-Step Floating Catchment Area

FINESS: National File on Health and Social Institutions

FGC: French Geographic Code unit

ISA: Spatial Accessibility Index

MCO: Medical, Surgical and Obstetrics

SAE: Annual Statistical Survey of Healthcare Facilities

SSR: Postoperative and Rehabilitation Care

LOS: Length Of Stay

\section{DECLARATIONS}

\section{ETHICS APPROVAL AND CONSENT TO PARTICIPATE}

Not applicable

\section{CONSENT FOR PUBLICATION}

Not applicable

\section{AVAILABILITY OF DATA AND MATERIAL}

All data generated or analyzed during this study are included in this published article. If readers need supplementary information, they can contact me (fei.gao@ehesp.fr). 


\section{COMPETING INTERESTS}

The authors declare that they have no competing interests.

\section{$\underline{\text { FUNDING }}$}

Not applicable.

\section{$\underline{\text { AUTHORS' CONTRIBUTIONS }}$}

FG designed the project, performed the statistical analysis and drafted the manuscript. SD supervised the overall project, oversaw the statistical analysis, and helped to draft and revised the manuscript. MJ performed the statistical analysis with FG and SD. All authors interpreted the data and reviewed the manuscript for important intellectual content. All authors have read and approved the final version of the manuscript.

\section{$\underline{\text { ACKNOWLEDGEMENTS }}$}

This research is supported by EHESP Rennes, REPERES-EA 7449, IPLESP and ENSAI. We are extremely grateful to JB Combes, M. PICHOT-UTRERA et A. TALEC for their commitment and their role in the success of the study. Points of view or opinions in this article are those of the authors and do not necessarily represent the official position or policies of the EHESP Rennes, REPERES-EA 7449, IPLESP and ENSAI.

\section{$\underline{\text { REFERENCES }}$}

[1] United Nations Transforming our world: The 2030 Agenda for Sustainable Development. Available online: https://sustainabledevelopment.un.org/post2015/transformingourworld/ (accessed on 25 September 2015). 
[2] Zhu L, Zhong S, Tu W, Zheng J, He S, Bao J, Huang C. Assessing Spatial Accessibility to Medical Resources at the Community Level in Shenzhen, China. Int J Environ Res Public Health. 2019 Jan 16;16(2). pii: E242. doi: 10.3390/ijerph16020242.

[3] Shah T, Bath B, Hayes A, Jones M, Bell S, Uswak G, Milosavljevic S. Comparative Analysis of Geographic Accessibility of Dentists, Physiotherapists and Family Physicians in an Urban Centre: A Case Study of Saskatoon, Canada. J Can Dent Assoc. 2019 Jul;85:j2. PMID: 32119638.

[4] Dussault G, Franceschini MC. Not enough there, too many here: understanding geographical imbalances in the distribution of the health workforce. Hum Resour Health. 2006 May 27;4:12. doi: 10.1186/1478-4491-4-12.

[5] McGrail MR. Spatial accessibility of primary health care utilising the two-step floating catchment area method: An assessment of recent improvements. Int. J. Health Geogr. 2012, $11,50$.

[6] Tang JH, Chiu YH, Chiang PH, Su MD, Chan, TC. A flow-based statistical model integrating spatial and nonspatial dimensions to measure healthcare access. Health Place. 2017 Sep;47:126-138. doi: 10.1016/j.healthplace.2017.08.006. Epub 2017 Sep 4.

[7] Hansen WG. How Accessibility Shapes Land Use. J. Am. Inst. Plan. 1959;25:73-76. doi:10.1080/01944365908978307.

[8] Kwan MP. Space-time and integral measures of individual accessibility: A comparative analysis using a point-based framework. Geogr. Anal. 1998;30:191-216. doi: 10.1111/j.15384632.1998.tb00396.x. 
[9] Kwan MP, Weber J. Scale and accessibility: Implications for the analysis of land use-travel interaction. Appl. Geogr. 2008;28:110-123. doi: 10.1016/j.apgeog.2007.07.002.

[10] Luo W, Wang F. Spatial accessibility to primary care and physician shortage area designation: a case study in Illinois with GIS approaches. In: Skinner, R., Khan, O. (Eds.), Geographic Information Systems and Health Applications. 2003. Idea Group Publishing, Hershey, PA, pp. 260-278.

[11] Pan X, Kwan MP, Yang L, Zhou S, Zuo Z, Wan B. Evaluating the Accessibility of Healthcare Facilities Using an Integrated Catchment Area Approach. Int J Environ Res Public Health. 2018;15(9):2051. Published 2018 Sep 19. doi:10.3390/ijerph15092051.

[12] Wang FH, Luo W. Assessing Spatial and Nonspatial Factors for Healthcare Access: Towards an Integrated Approach to Defining Health Professional Shortage Areas. Health \& Place 2015, 11(2):131-46. doi: 10.1016/j.healthplace.2004.02.003.

[13] Berke, Ethan \& Shi, Xun. (2009). Computing travel time when the exact address is unknown: A comparison of point and polygon ZIP code approximation methods. International journal of health geographics. 8. 23. 10.1186/1476-072X-8-23.

[14] Héquette-Ruz R, Beuscart JB, Ficheur G, Chazard E, Guillaume E, Paccou J, Puisieux F, Genin M. Hip fractures and characteristics of living area: a fine-scale spatial analysis in France. Osteoporos Int. 2020 Mar 5. doi: 10.1007/s00198-020-05363-7.

[15] Graham S, Hallisey E, Wilt G, Flanagan B, Rodriguez JL, Peipins L. Sociodemographic disparities in access to ovarian cancer treatment. Ann Cancer Epidemiol. 2019 Nov;3. doi: 10.21037/ace.2019.10.02. Epub 2019 Nov 27. 
[16] Buchmueller TC, Jacobson M, Wold C. How far to the hospital? The effect of hospital closures on access to care. J. Health Econ. 2006, 25, 740-761.

[17] Wang F, McLafferty S, Escamilla V, Luo L. Late-Stage Breast Cancer Diagnosis and Health Care Access in Illinois. Prof Geogr. 2008 Feb;60(1):54-69. doi: 10.1080/00330120701724087. [18] Alkire BC, Raykar NP, Shrime MG, Weiser TG, Bickler SW, Rose JA, Nutt CT. Greenberg SLM, Kotagal M, Riesel JN et al. Global access to surgical care: A modelling study. Lancet Glob Health. 2015 Jun;3(6):e316-23. doi: 10.1016/S2214-109X(15)70115-4. Epub 2015 Apr 27.

[19] Clarke JR, Trooskin SZ, Doshi PJ, Greenwald L, Mode CJ. Time to laparotomy for intraabdominal bleeding from trauma does affect survival for delays up to 90 minutes. J Trauma. 2002 Mar;52(3):420-5. doi: 10.1097/00005373-200203000-00002.

[20] https://www.cleiss.fr/particuliers/venir/soins/ue/systeme-de-sante-en-france_en.html. Accessed 12 April 2020.

[21] Gandré C, Gervaix J, Thillard J, Macé JM, Roelandt JL, Chevreul K. The Development of Psychiatric Services Providing an Alternative to Full-Time Hospitalization Is Associated with Shorter Length of Stay in French Public Psychiatry. Int J Environ Res Public Health. 2017 Mar; 14(3): 325. Published online 2017 Mar 21. doi: 10.3390/ijerph14030325.

[22] Karpiel MS. Using patient classification systems to identify ambulatory care costs. CBS Business Network. Retrieved 25 July 2011.

[23] Berman P. Organization of ambulatory care provision: a critical determinant of health system performance in developing countries. Bulletin of the World Health Organization. 2000. 78 (6): 791-802. PMC 2560790. PMID 10916916. 
[24] Institute of Medicine (US) Committee on the Future of Primary Care, Donaldson MS, Yordy KD, Lohr KN, Vanselow NA, eds. Primary Care: America's Health in a New Era. Washington (DC): National Academies Press (US); 1996.

[25] World Health Organization. (2018). Continuity and coordination of care: a practice brief to support implementation of the WHO Framework on integrated people-centred health services. World Health Organization. https://apps.who.int/iris/handle/10665/274628.

[26] Hospital discharges and length of stay statistics. Eurostat:

https://data.oecd.org/healthcare/hospital-discharge-rates.htm. Accessed 14 April 2020.

[27] Committee on Guidance for Establishing Crisis Standards of Care for Use in Disaster Situations; Institute of Medicine. Crisis Standards of Care: A Systems Framework for Catastrophic Disaster Response. Washington (DC): National Academies Press (US); 2012 Mar 21. 8, Out-of-Hospital and Alternate Care Systems. Available from:

\section{https://www.ncbi.nlm.nih.gov/books/NBK201069/}

[28] Sills MR, Hall M, Simon HK, Fieldston ES, Walter N, Levin JE, Brogan TV, Hain PD, Goodman DM, Fritch-Levens DD, Fagbuyi DB, Mundorff MB, Libby AM, Anderson HO, Padula WV, Shah SS. Resource burden at children's hospitals experiencing surge volumes during the spring 2009 H1N1 influenza pandemic. Academic Emergency Medicine. 2011;18(2):158-166.

[29] Nunes AM, Ferreira DC. Reforms in the Portuguese health care sector: Challenges and proposals. Int J Health Plann Manage. 2019 Jan;34(1):e21-e33. doi: 10.1002/hpm.2695. Epub 2018 Oct 28. PMID: 30370564. 
[30] Les établissements de santé - édition 2017 | https://drees.solidarites-

sante.gouv.fr/etudes-et-statistiques/publications/communiques-de-presse/article/12-4-

millions-de-patients-hospitalises-en-2015.

[31] Higgs G. The role of GIS for health utilization studies: literature review. Health Services Outcomes Res Methodology. 2009;9:84-99. doi: 10.1007/s10742-009-0046-2.

[32] Delamater PL, Shortridge AM, Kilcoyne RC. Using floating catchment area (FCA) metrics to predict health care utilization patterns. BMC Health Serv Res. 2019;19(1):144. Published 2019 Mar 4. doi:10.1186/s12913-019-3969-5.

[33] Kjekshus, L. E. (2005). Primary health care and hospital interactions: Effects for hospital length of stay. Scandinavian Journal of Public Health, 33(2), 114-122.

doi:10.1080/14034940410019163.

[34] United Nations, Department of Economic and Social Affairs, Population Division (2019). World Population Ageing. (ST/ESA/SER.A/430). New York: United Nations; (2019).

[35] Institut national de la statistique et des études économiques. INSEE population: https://www.insee.fr/fr/statistiques/1906664?sommaire=1906743. Accessed 2 December 2020.

[36] Barlet M, Coldefy M, Collin C, Lucas-Gabrielli V. L'Accessibilité potentielle localisée (APL) : une nouvelle mesure de l'accessibilité aux médecins généralistes libéraux. Institut de recherche et documentation en économie de la santé. 2012;174.

[37] Lucas-Gabrielli V, Mangeney C. Comment améliorer les mesures d'accessibilité aux soins pour mieux cibler les zones sous-denses ? Revue d'Épidémiologie et de Santé Publique,Volume 67, Supplement 1,2019. doi:10.1016/j.respe.2018.12.061. 
[38] Gao F, Kihal W, Le Meur N, Souris M, Deguen S. Assessment of the spatial accessibility to health professionals at French census block level. Int J Equity Health. 2016;15(1):125. doi: 10.1186/s12939-016-0411-z.

[39] Gao F, Kihal W, Le Meur N, Souris M, Deguen S. Does the edge effect impact on the measure of spatial accessibility to healthcare providers? Int J Health Geogr. 2017; 16: 46. Published online 2017 Dec 11. doi: 10.1186/s12942-017-0119-3

[40] Localized Potential Accessibility (APL) database:

http://www.data.drees.sante.gouv.fr/ReportFolders/reportFolders.aspx?IF_ActivePath=P,49 0,530. Accessed 12 march 2018.

[41] Annual Statistical Survey of Healthcare Facilities (SAE) database: https://www.saediffusion.sante.gouv.fr/sae-diffusion/recherche.htm. Accessed 1st April 2018.

[42] National File on Health and Social Institutions (FINESS) database: http://finess.sante.gouv.fr/fininter/jsp/recherche.jsp?mode=simple. Accessed 1st April 2018.

[43] French National Address database https://adresse.data.gouv.fr/. Accessed 12 march 2018.

[44] Exposto F, Petrică N, Davies E, Beaudet A. Identification of a pulmonary arterial hypertension (PAH) patient cohort and study of its burden of illness in Programme de Médicalisation des Systèmes d'information (PMSI). Int J Cardiol. 2020 Feb 13. pii: S01675273(19)34942-3. doi: 10.1016/j.ijcard.2020.02.034. 
[45] Charles-Nelson A, Lazzati A, Katsahian S. Obes Surg. Analysis of Trajectories of Care After Bariatric Surgery Using Data Mining Method and Health Administrative Information Systems. 2020 Feb 6. doi: 10.1007/s11695-020-04430-6.

[46] Lamarsal le L, Hunt B, Schauf M, Szwarcensz tein K, Valentine WJ. Evaluating the clinical and economic burden of healthcar e-associate $d$ infections during hospitaliza tion for surgery in France. Epidemiol Infect. 2013 Dec;141(12):2473-82. doi: 10.1017/S0950268813000253. Epub 2013 Feb 28.

[47] Fourquet F, Demont F, Lecuyer Al, Rogers MA, Bloc DH. French medical hospital information system and cross infection surveillance: theory and feasibility. Médecine Mal Infect. 2003; 33(2):110- 3. https:// doi.org/10.10 16/s0399-077x (02)00005 -7.

[48] Institut national de la statistique et des études économiques : http://www.insee.fr/fr/. Accessed 2 may 2018.

[49] Luo W, Qi Y. An enhanced two-step floating catchment area (E2SFCA) method for measuring spatial accessibility to primary care physicians. Health Place. 2009 Dec;15(4):1100-7. doi: 10.1016/j.healthplace.2009.06.002.

[50] Zdeb M. Driving Distances and Times Using SAS ${ }^{\circledR}$ and Google Maps. SAS Global Forum 2010.

[51] Jenks, George F. 1967. "The Data Model Concept in Statistical Mapping", International Yearbook of Cartography 7: 186-190

[52] Bindman AB, Grumbach K, Osmond D, Komaromy M, Vranizan K, Lurie N, Billings J, Stewart A. Preventable Hospitalizations and Access to Health Care. Journal of the American Medical Association. 1995;274(4):305-11. 
[53] Goodman DC, Fisher E, Stukel TA, Chang C. The Distance to Community Medical Care and the Likelihood of Hospitalization: Is Closer Always Better? American Journal of Public Health. 1997;87(7):1144-50.

[54] Ricketts TC, Randolph R, Howard HA, Pathman D, Carey T. Hospitalization Rates as Indicators of Access to Primary Care. Health \& Place. 2001;7:27-38.

[55] Fortney JC, Steffick DE, Burgess JF Jr, Maciejewski ML, Petersen LA. Are primary care services a substitute or complement for specialty and inpatient services?. Health Serv Res. 2005;40(5 Pt 1):1422-1442. doi:10.1111/j.1475-6773.2005.00424.x

[56] Wang X, Pan J. Assessing the disparity in spatial access to hospital care in ethnic minority region in Sichuan Province, China. BMC Health Serv Res. 2016 Aug 17;16(1):399. doi: 10.1186/s12913-016-1643-8.

[57] Nakamura T, Nakamura A, Mukuda K, Harada M, Kotani K. Potential accessibility scores for hospital care in a province of Japan: GIS-based ecological study of the two-step floating catchment area method and the number of neighborhood hospitals. BMC Health Serv Res. 2017 Jun 26;17(1):438. doi: 10.1186/s12913-017-2367-0.

[58] Ye H, Lee S, Kim H. Effects of Neighborhood Characteristics on Length of Inpatient Stay: Findings from the U.S. National Data. Soc Work Res. 2016 Jun;40(2):117-126. Epub 2016 Mar 28.

[59] Batten AJ, Augustine MR, Nelson KM, Kaboli PJ. Development of a novel metric of timely care access to primary care services.Health Serv Res. 2020 Apr;55(2):301-309. doi: 10.1111/1475-6773.13255. Epub 2020 Jan 14. 
[60] Yuan Y, Cave M, Xu H, Zhang C. Exploration of spatially varying relationships between Pb and $\mathrm{Al}$ in urban soils of London at the regional scale using geographically weighted regression (GWR). J Hazard Mater. 2020 Feb 22;393:122377. doi:

10.1016/j.jhazmat.2020.122377.

[61] Chan J, Polo A, Zubizarreta E, Bourque JM, Hanna TP, Gaudet M, Dennis K, Brundage M, Slotman B, Abdel-Wahab M. Access to radiotherapy and its association with cancer outcomes in a high-income country: Addressing the inequity in Canada.Radiother Oncol. 2019 Dec;141:48-55. doi: 10.1016/j.radonc.2019.09.009.

[62] Burkner P. brms: An R package for Bayesian Multilevel Models using Stan. J Stat Softw. 2017;80(1):1-28.

[63] Nicholas J. Tierney, Antonietta Mira, H. Jost Reinhold, Giuseppe Arbia, Samuel Clifford, Angelo Auricchio, Tiziano Moccetti, Stefano Peluso, Kerrie L. Mengersen. Evaluating health facility access using Bayesian spatial models and location analysis methods. PLoS One. 2019; 14(8): e0218310. Published online 2019 Aug 7. doi: 10.1371/journal.pone.0218310. 


\section{$\underline{\text { LIST OF TABLES }}$}

Table 1: Variable description.

\begin{tabular}{lll}
\hline VARIABLES & DESCRIPTION & category of facilities \\
\hline $\begin{array}{l}\text { Dependent variable } \\
\text { LOS_MCO/LOS_SSR }\end{array}$ & $\begin{array}{l}\text { The mean hospital stay length in MCO or SSR of elderly } \\
\text { people ( } \geq 75 \text { years of age) relative to the total } \geq 75 \text {-year-old } \\
\text { population }\end{array}$ & Hospital \\
\hline $\begin{array}{l}\text { Independent variables } \\
\text { ISA_MCO/ISA_SSR }\end{array}$ & $\begin{array}{l}\text { Index of spatial accessibility to MCO and SSR facilities } \\
\text { Localized Potential Accessibility to general practitioners } \\
\text { APL_GPS }\end{array}$ & Hospital \\
APL_Nurses & $\begin{array}{l}\text { Localized Potential Accessibility to home-visiting nurses } \\
\text { Localized Potential Accessibility to physiotherapists }\end{array}$ & Non-hospital \\
Composite_APL & $\begin{array}{l}\text { Built from APL_GPS, APL_Nurses and APL_Physiotherapists } \\
\text { Using principal component analysis }\end{array}$ & Non-hospital \\
\hline
\end{tabular}

Table 2: Descriptive analysis of the Index of Spatial Accessibility (ISA) for MCO and SSR.

Nord administrative region (expressed for 10000 inhabitants).

\begin{tabular}{cccccccc}
\hline & N & Min & Mean (Sd) & Max & 25th & Median & 75th \\
\hline MCO & 240 & 0.44 & $19.0(10.69)$ & 39.28 & 10.28 & 14.32 & 29.41 \\
\hline SSR & 240 & 0.03 & $5.58(2.19)$ & 9.00 & 4.25 & 6.33 & 7.25 \\
\hline
\end{tabular}

Sd, standard deviation

Table 3. LOS of $\geq 75$-year-old people in MCO and SSR facilities - Nord administrative region.

\begin{tabular}{cccccccc}
\hline & $\mathbf{N}$ & Min & Mean (Sd*) & Max & 25th & Median & 75th \\
\hline MCO & 240 & 0.01 & $0.26(0.20)$ & 1.68 & 0.10 & 0.20 & 0.37 \\
\hline SSR & 240 & 0.03 & $0.85(0.92)$ & 10.98 & 0.33 & 0.65 & 1.08 \\
\hline
\end{tabular}

* Standard deviation

Table 4: Summary of the two regressions models: the LOS_MCO and LOS_SSR sCores at FGC scale.

\begin{tabular}{ccc}
\hline & [LOS_MCO]_hospital & [LOS_SSR]_hospital \\
\hline [Composite_APL]_non-hospital & $-1.141^{* * *}$ & $-1.379^{* * *}$ \\
\hline [ISA_MCO]_hospital & $-.283^{* *}$ & $\mathrm{NA}$ \\
\hline [ISA_SSR]_hospital & $\mathrm{NA}$ & .045 \\
\hline Observations & 240 & 239 \\
\hline $\mathbf{R}^{\mathbf{2}}$ & 0.134 & 0.082 \\
\hline VIF & $<1.17$ & $<1.13$ \\
\hline${ }^{* *} p<0.01 ; * * *$ & $p<0.001 ; \mathrm{R}^{2}:$ determination coefficient; VIF: Variance Inflation Factor; NA: Not applicable
\end{tabular}




\section{FIGURE LEGENDS}

Fig. 1 Spatial distribution of the Index of Spatial Accessibility at the FCG level.

(a) Index of Spatial Accessibility for Medical, Surgical and Obstetrics (MCO) and (b) Post-operative and Rehabilitation Care (SSR) centers. For each map, the French neighboring administrative regions are colored in green, whereas the Nord administrative region is represented using a graduated color approach, to highlight the different ISA scores.

Fig. 2 Distribution of the $\geq 75$-year-old population at the FGC level in Nord administrative region in 2016.

Fig. 3 MCO LOS spatial distribution for $\geq 75$-year-old people at the FGC level.

LOS for Medical, Surgical and Obstetrics (MCO) centers

Fig. 4 SSR LOS spatial distribution for $\geq 75$-year-old people at the FGC level.

LOS for Post-operative and Rehabilitation Care (SSR) centers 


\section{Figures}

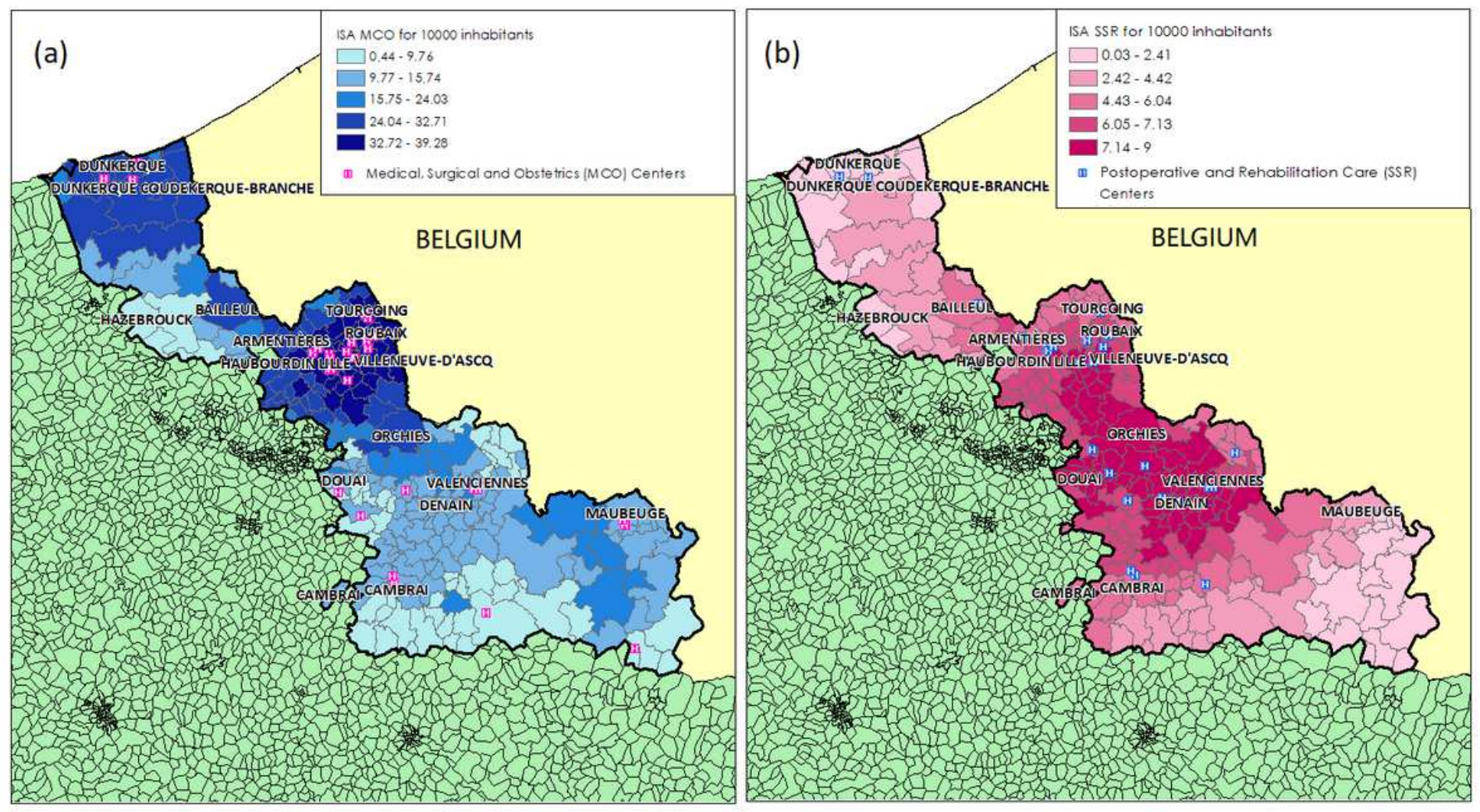

Figure 1

Spatial distribution of the Index of Spatial Accessibility at the FCG level. (a) Index of Spatial Accessibility for Medical, Surgical and Obstetrics (MCO) and (b) Post-operative and Rehabilitation Care (SSR) centers. For each map, the French neighboring administrative regions are colored in green, whereas the Nord administrative region is represented using a graduated color approach, to highlight the different ISA scores. 


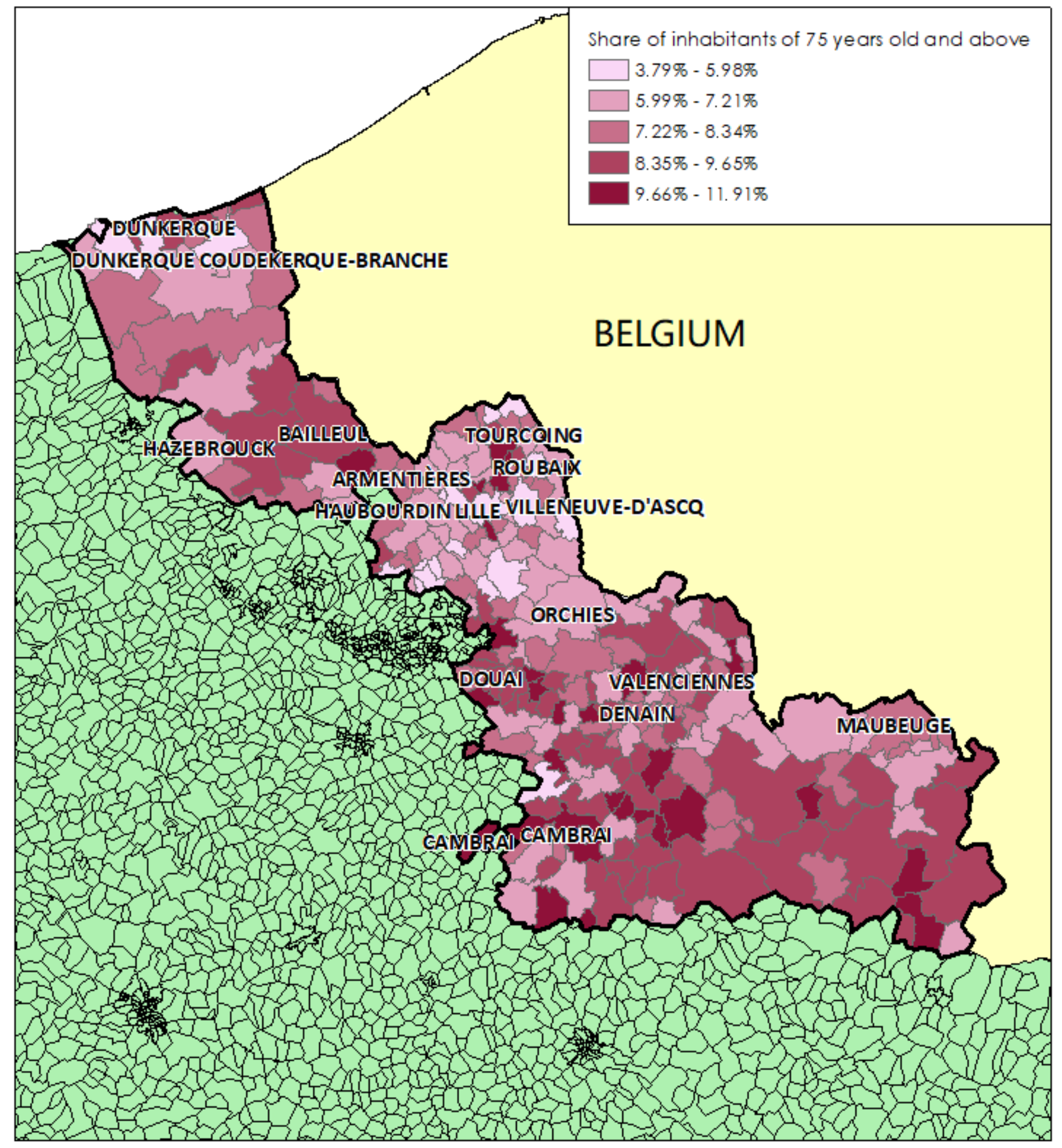

Figure 2

Distribution of the $\geq 75$-year-old population at the FGC level in Nord administrative region in 2016 . 


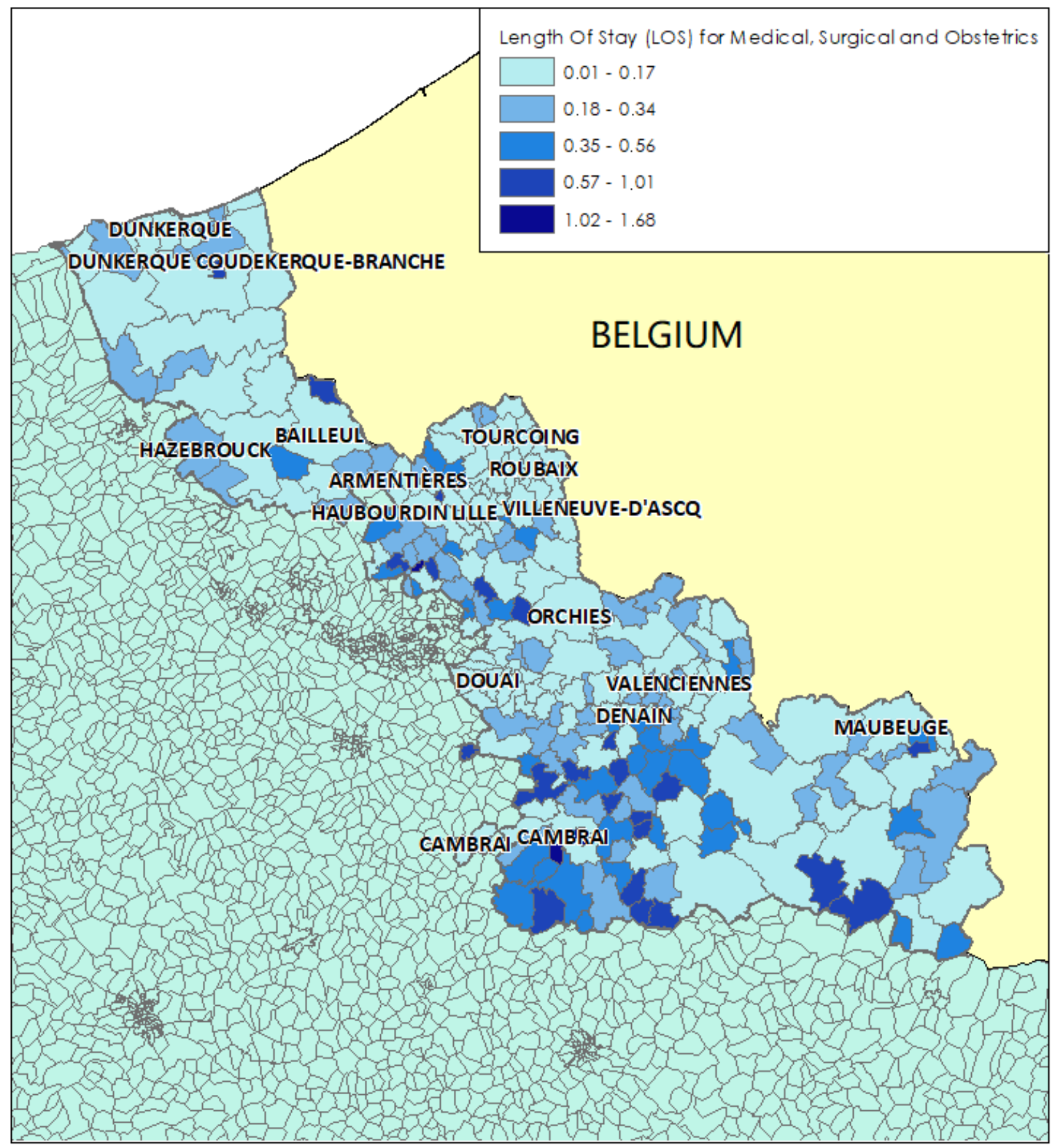

Figure 3

MCO LOS spatial distribution for $\geq 75$-year-old people at the FGC level. LOS for Medical, Surgical and Obstetrics (MCO) centers 


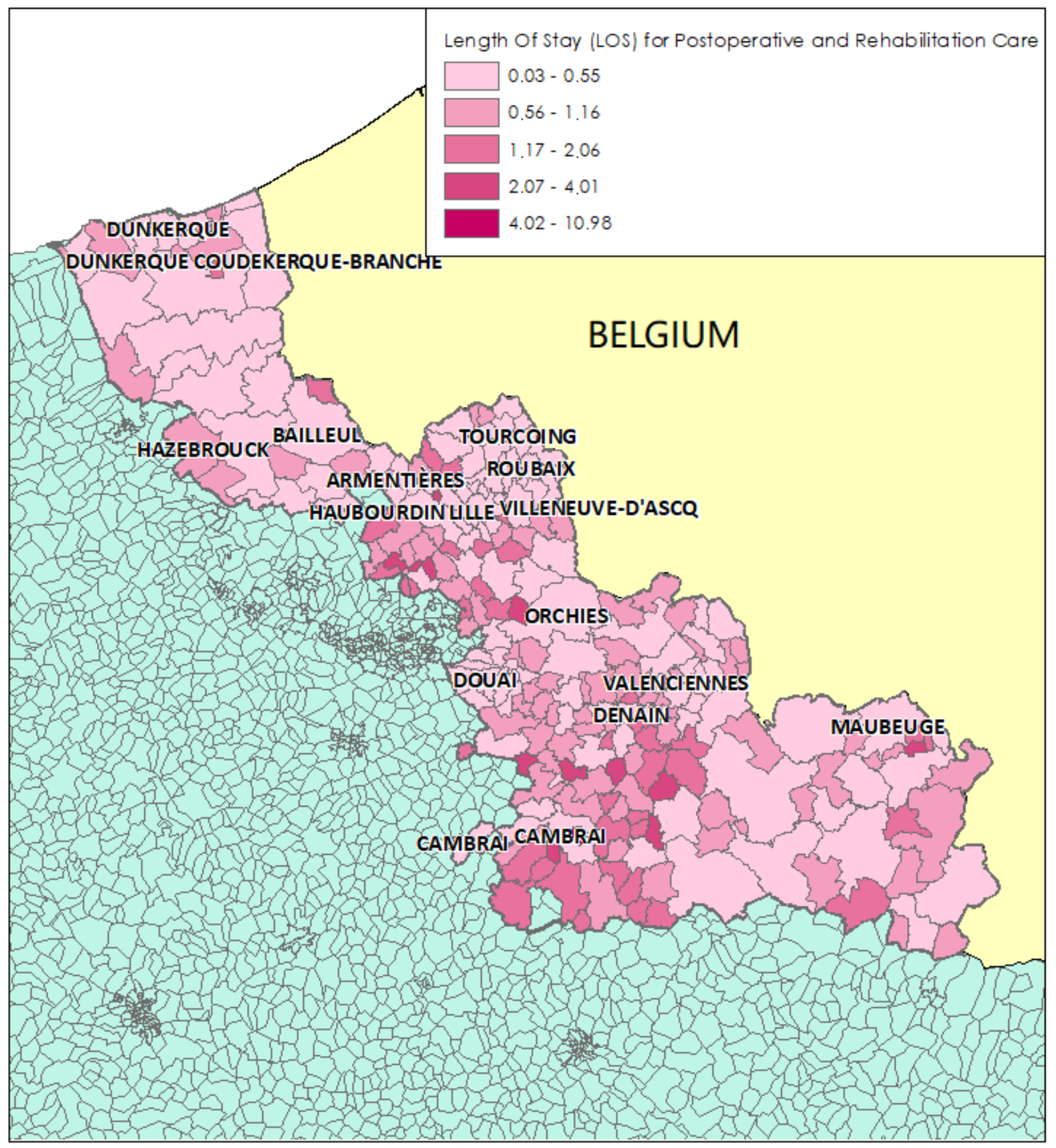

\section{Figure 4}

SSR LOS spatial distribution for $\geq 75$-year-old people at the FGC level. LOS for Post-operative and Rehabilitation Care (SSR) centers 